Daniel Jose C. Mendoza, MD Samantha S. Castaneda, MD Antonio H. Chua, MD

Department of Otorhinolaryngology Head and Neck Surgery

Jose R. Reyes Memorial Medical Center
Correspondence: Dr. Daniel Jose C. Mendoza

Department of Otorhinolaryngology

Head and Neck Surgery

Jose R. Reyes Memorial Medical Center

San Lazaro Compound, Rizal Avenue

Sta. Cruz, Manila 1003

Philippines

Phone: (632) 7436921 (632) 7119491 local 320

Email:wapi_21@hotmail.com

Reprints will not be available from the author

The authors declared that this represents original material that is not being considered for publication or has not been published or accepted for publication elsewhere in full or in part, in print or electronic media; that the requirements for authorship have been met by each author, and that each author believes that the manuscript represents honest work.

Disclosures: The authors signed disclosures that there are no financial or other (including personal) relationships, intellectual passion, political or religious beliefs, and institutional affiliations that might lead to a conflict of interest.

Presented at Philippine Society of Otolaryngology-Head and Neck Surgery, Descriptive Research Contest (1st Place), September 19, 2013, Natrapharm, The Patriot Bldg., KM 18 SLEX, Paranaque City.

\section{Intraoperative Distance Between the Main Trunk of the Facial Nerve and Surgical Landmarks Used in Parotidectomy: A Prospective Study}

\begin{abstract}
Objective: To determine the mean distance of the main trunk of the facial nerve from two commonly employed surgical landmarks (tragal pointer and tympanomastoid suture line) among a sample of Filipino adults undergoing parotidectomy.
\end{abstract}

\section{Methods:}

Design: Prospective Descriptive Study

Setting: Tertiary Government Training Hospital

Subjects: 22 patients without facial paralysis undergoing surgery for parotid neoplasms were evaluated intraoperatively.

Results: The main trunk of the facial nerve was found to be $9.0 \mathrm{~mm}$ (standard deviation of $2.8 \mathrm{~mm}$ ) from the tragal pointer and $6.1 \mathrm{~mm}$ (standard deviation of $2.0 \mathrm{~mm}$ ) from the tympanomastoid suture line.

Conclusion: The mean distance from the main trunk of the facial nerve to two of the most commonly utilized landmarks in identification of the nerve during parotidectomy was $9.0 \mathrm{~mm}$ (standard deviation of $2.8 \mathrm{~mm}$ ) from the tragal pointer and $6.1 \mathrm{~mm}$ (standard deviation of $2.0 \mathrm{~mm}$ ) from the tympanomastoid suture line. These may serve as reference values for surgeons in safer identification and preservation of the facial nerve during parotidectomy.

Keywords: facial nerve, parotidectomy, tragal pointer, tympanomastoid suture line, anatomic landmarks

The facial nerve and the parotid gland share an intimate anatomic relationship. The gland is divided into superficial and deep lobes by a sagittal plane defined by the branches of the nerve. However, the gland is actually unilobar and the plane created by the fanning branches of the facial nerve is not a true anatomic separation into two distinct and discrete lobes. ${ }^{1}$

During parotidectomy, several anatomical landmarks may be used to locate the facial nerve. One of the most commonly employed is the tragal pointer. The facial nerve is approximately 1 to $1.5 \mathrm{~cm}$ deep and inferior to it. ${ }^{2}$ Another landmark used is the tympanomastoid suture line. It is about 6 to $8 \mathrm{~mm}$ deep or medial to the nerve. ${ }^{3}$ This is considered to be the most reliable landmark. ${ }^{4}$ Other landmarks may be used such as tip of the mastoid process and the central point of the transverse process of the atlas which are bony projections. ${ }^{5}$

To the best of our knowledge, there are limited if any local studies on the use of these landmarks during parotid surgery on Filipinos. This study aims to determine the mean distances 
ORIGINAL ARTICLES

Philipine Journal Of Otolaryngology-Head And Neck Surgery

Vol. 29 No. 1 JANUARY - JUNE 2014

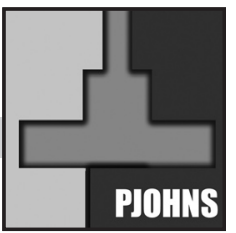

of the two most commonly used landmarks, the tragal pointer and the tympanomastoid suture line from the main trunk of facial nerve during parotidectomy.

\section{METHODS}

Study Design: Prospective descriptive study from April 2012May 2013

Setting: Tertiary government hospital

Subjects: Twenty-two patients aged 18 and above with parotid neoplasms and no facial paralysis and who gave informed consent were included in the study.

Procedure: Under general anesthesia and endotracheal intubation, patients were placed in supine position with the head rotated to the contralateral side of the parotid tumor. A modified Blair incision was carried out, skin flaps were developed and the parotid gland was exposed.

The tragal pointer, a downward-protruding cartilaginous portion of the tragus was identified. This was followed by identifying the tympanomastoid suture line, a v-shaped sulcus between the antero inferior margin of the external auditory canal and the anterior margin of the mastoid process of the temporal bone. Dissection was done to identify the main trunk of the facial nerve as shown in Figure 1.

Measurements from the two landmarks (Figure 2) were taken once the main trunk of the facial nerve was identified prior to excision of the mass using a surgical legged caliper (HUCO Vision SA, Switzerland) as follows:

- tragal pointer: the shortest distance from the main trunk of the facial nerve to the most inferior and anterior portion of the tragal pointer;

- tympanomastoid suture line: the shortest distance from the main trunk of the facial nerve to the most anterior aspect of the palpable v-shaped sulcus; and
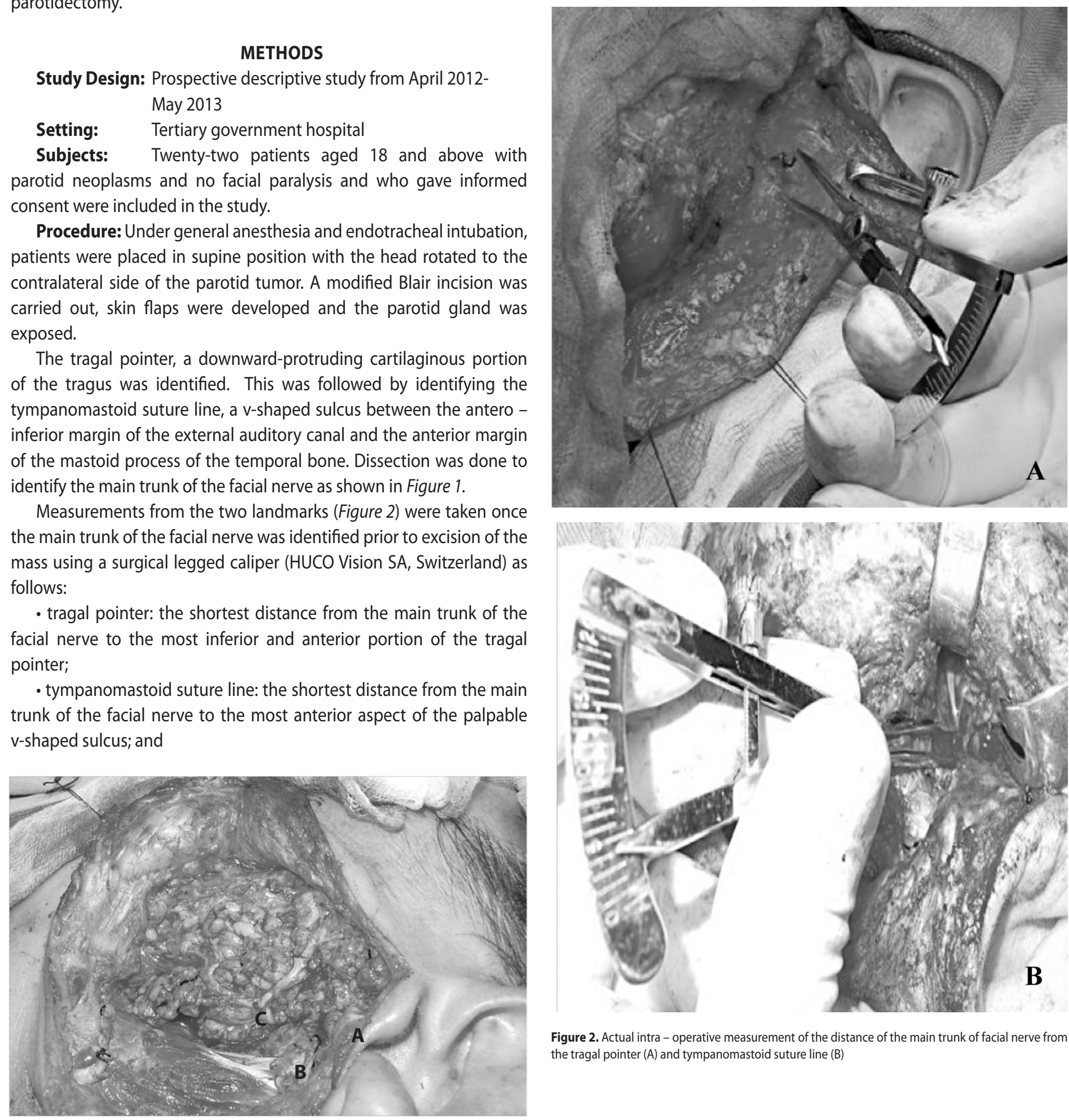

Figure 2. Actual intra - operative measurement of the distance of the main trunk of facial nerve from the tragal pointer $(A)$ and tympanomastoid suture line $(B)$

Figure 1. Identification of tragal pointer (A), tympanomastoid suture line (B), and main trunk of facial nerve $(C)$ 
- main trunk of the facial nerve: the extracranial segment of the facial nerve as it enters the parotid tissue

Excision of the mass was completed which involved either superficial or total parotidectomy. Standard hemostasis and closure were performed.

Data and Statistical Analysis: Data taken were recorded and tabulated. The mean and standard deviation of the measurements from the two landmarks of interest were obtained using MS Excel (Microsoft Corporation, Redmond, WA, USA).

Table 1. Distance of the main trunk of the facial nerve to tragal pointer and tympanomastoid suture line. $(n=22)$

\begin{tabular}{|l|c|c|}
\hline & Tragal pointer & $\begin{array}{c}\text { Tympanomastoid } \\
\text { suture line }\end{array}$ \\
\hline Mean $(\mathrm{mm})$ & 9.0 & 6.1 \\
\hline Standard deviation $(\mathrm{mm})$ & 2.8 & 2.0 \\
\hline Mode $(\mathrm{mm})$ & 8.0 & 4.0 \\
\hline Min $(\mathrm{mm})$ & 5.0 & 4.0 \\
Max $(\mathrm{mm})$ & 18.0 & 10.0 \\
\hline
\end{tabular}

Table 2. Distance of the main trunk of the facial nerve to tragal pointer and tympanomastoid suture line among males and females. $(n=22 ;$ males $=8$; females $=14$ )

\begin{tabular}{|c|c|c|c|c|}
\hline & \multicolumn{2}{|c|}{ Tragal pointer } & \multicolumn{2}{c|}{$\begin{array}{c}\text { Tympanomastoid } \\
\text { suture line }\end{array}$} \\
\cline { 2 - 5 } & Males & Females & Males & Females \\
\hline Mean (mm) & 8.5 & 9.4 & 6.0 & 6.1 \\
\hline Standard deviation (mm) & 2.1 & 3.1 & 1.9 & 2.2 \\
\hline Mode (mm) & 7.0 & 8.0 & 4.0 & 6.0 \\
\hline Min (mm) & 6.0 & 5.0 & 4.0 & 4.0 \\
\hline Max (mm) & 12.0 & 18.0 & 9.0 & 10.0 \\
\hline
\end{tabular}

Table 3. Comparison of the mean distance of the main trunk of facial nerve to tragal pointer and tympanomastoid suture line among males and females

\begin{tabular}{|c|c|c|c|c|}
\hline & \multicolumn{2}{|c|}{ Tragal pointer } & \multicolumn{2}{c|}{$\begin{array}{c}\text { Tympanomastoid } \\
\text { suture line }\end{array}$} \\
\cline { 2 - 5 } & Males & Females & Males & Females \\
\hline Our result $(\mathbf{m m})$ & 8.5 & 9.4 & 6.0 & 6.1 \\
\hline Rea, et al ${ }^{\mathbf{6}}(\mathrm{mm})$ & 6.7 & 7.1 & 2.3 & 2.6 \\
\hline Pather, et al ${ }^{11}(\mathrm{~mm})$ & 39.4 & 40.6 & 9.9 & 10.1 \\
\hline
\end{tabular}

\section{RESULTS}

There were 22 patients included in the study, 8 males and 14 females with ages ranging from 22 to 71 years old. Of the 22 patients, 1 underwent total parotidectomy while the remaining 21 had superficial parotidectomy.

The mean distance of the main trunk of the facial nerve to the tragal pointer was $9.0 \mathrm{~mm}$ with standard deviation of $2.8 \mathrm{~mm}$. On the other hand, the mean distance of the tympanomastoid suture line from the main trunk of facial nerve was $6.1 \mathrm{~mm}$ with standard deviation of 2.0 $\mathrm{mm}$. (Table 1)

The mean distances of the main trunk of facial nerve from the tragal pointer and tympanomastoid suture line were $8.5 \mathrm{~mm}$ and $6.0 \mathrm{~mm}$ for males, respectively. For females, the tragal pointer and tympanomastoid suture line were $9.5 \mathrm{~mm}$ and $6.1 \mathrm{~mm}$ away from the main trunk of facial nerve, respectively. (Table 2)

\section{DISCUSSION}

This study aimed to measure the mean distance of the main trunk of the facial nerve from commonly employed surgical landmarks in parotidectomy, the tragal pointer and the tympanomastoid suture line. Similar studies comparing the distances of tragal pointer and tympanomastoid suture line from the main trunk of the facial nerve have varying results as seen in Figure 3.

Since many Filipinos have relatively smaller stature than Caucasians, it may be postulated that the distance of the main trunk of facial nerve to the landmarks should also be shorter. However, studies by Rea et al. and De Ru et al. showed shorter distances than our results, which may be explained by their use of cadavers as subjects. The cadavers were preserved and fixed using formaldehyde. Embalming may have desiccated the tissues altering texture and pliability. ${ }^{4}$ Thus, the measurements obtained would be shorter due to volume loss as compared to our subjects. Rea et al. also reflected the ears and removed the sternocleidomastoid muscles, both not representative of the intraoperative situation. ${ }^{6}$ Cadavers also have limited head rotation compared to living subjects. These factors may all contribute to differences in the results.

Another possible reason may be the presence of parotid tumors in our subjects compared to the subjects used in similar studies which did not have parotid tumors. The tumor may displace the facial nerve either toward or away from the landmarks of interest.

We evaluated the measurements according to gender. The mean distances of the facial nerve trunk of male subjects from the tragal pointer and tympanomastoid suture line were $8.5 \mathrm{~mm}$ and $6.0 \mathrm{~mm}$, respectively. Females had mean distances of $9.5 \mathrm{~mm}$ from the tragal pointer and $6.1 \mathrm{~mm}$ from the tympanomastoid suture line to the main trunk of the facial nerve. Our results are consistent with the literature, which shows that the facial nerve in males had a shorter distance from the two operative landmarks in comparison to females.

Rea et al. postulated that the difference is mainly due to the 


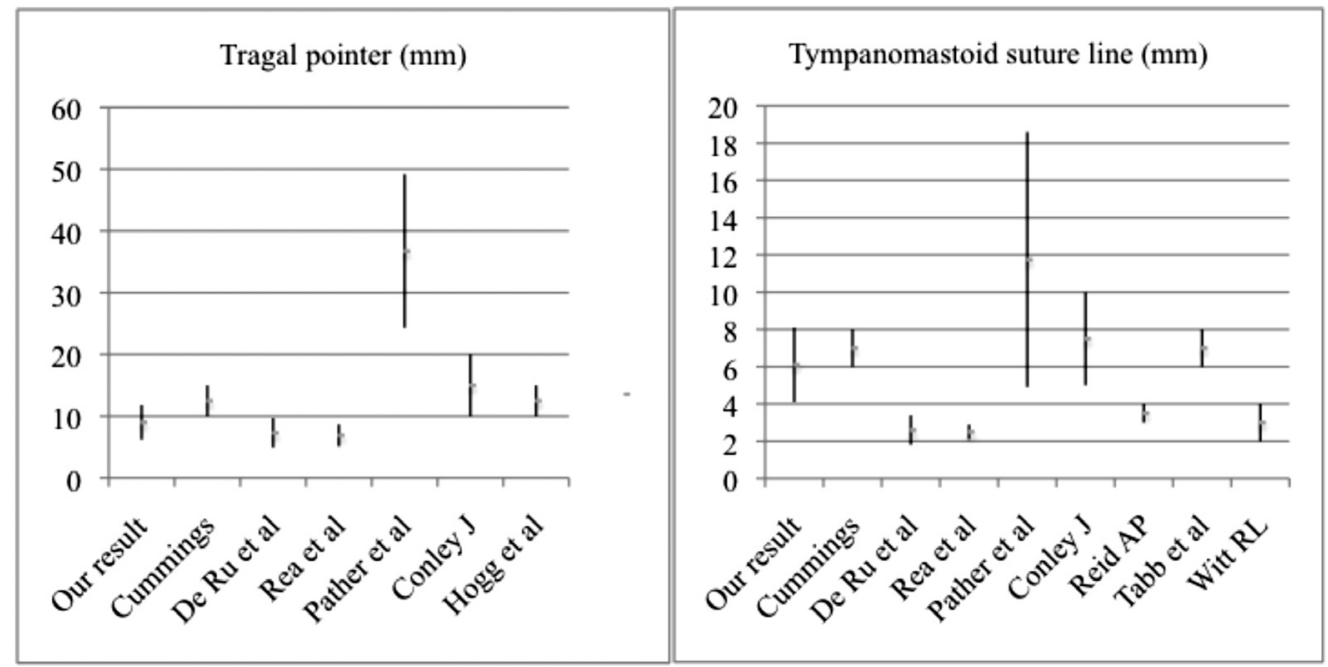

Figure 3. Comparison of the mean and range of distance of the tragal pointer and tympanomastoid suture line from the main trunk of facial nerve in different studies.

anatomic variation of the skulls of males and females. The male skull is more robust with larger mastoid process, deeper mandibular ramus, larger nuchal crest rigidity and rugose muscle attachments. ${ }^{6}$ Further studies may need to be done to determine such discrepancies in the measurements.

The use of landmarks and their relative distances to the facial nerve should be applied to minimize one of the complications during parotidectomy which is facial paralysis. Studies show that the prevalence rate of facial paralysis is variable ranging from $18.7 \% \%^{7}$ to $26.08 \%{ }^{8}$ and can be as high as $57 \%$ for transient facial paralysis. ${ }^{9}$ Permanent facial paralysis is reported from about 2 to $7 \% .{ }^{9}$ The risk for facial paralysis increases with total parotidectomy. ${ }^{10}$

A study by Dimitrov on 37 patients with parotid tumors who underwent conservative or lateral parotidectomy using the insertion of the posterior belly of the digastric muscle on the mastoid tip process and tympanomastoid fissure as anatomic landmarks in identifying the facial nerve found that these landmarks are easily recognizable and reliable start-points in facial nerve dissection that reduce the risk of traumatic injury of the nerve during parotid surgery. ${ }^{10}$

To prevent transient or even permanent facial nerve paralysis, it is a must for the surgeon to be knowledgeable of the surgical anatomy and exercise utmost care during surgery. We hope the distances we measured in our study may serve as reference values for surgeons in safer identification and preservation of the facial nerve during parotidectomy.

\section{REFERENCES}

1. Sunwoo J, Lewis J, McJunkin J, Sequeira S. Malignant neoplasms of the salivary glands. In: Flint P, Haughey B, Lund V, Niparko J, Richardson M, Robbins KT et al, editors. Cummings Otolaryngology Head and Neck Surgery. $5^{\text {th }}$ ed. Philadelphia: Mosby Elsevier. 2010. p.1194-5.

2. Caldaza G, Hanna E. Benign neoplasms of the salivary glands. In: Flint $P$, Haughey $B$, Lund $V$, Niparko J, Richardson M, Robbins KT et al, editors. Cummings Otolaryngology Head and Neck Surgery. $5^{\text {th }}$ ed. Philadelphia: Mosby Elsevier. 2010. p.1172-3.

3. Hogg SP, Kratz RC. Surgical exposure of the facial nerve. Arch Otolaryngol. 1958. 67: 560-1.

4. De Ru JA, van Benthem PP, Bleys RL, Lubsen H, Hordijk GJ. Landmarks for parotid surgery. J Laryngol Otol. 2001 Feb; 115(2): 122-5.

5. Greyling LM, Glanvill R, Boon JM, Schabort D, Meiring JH, Pretorius JP, et al. Bony landmarks as an aid for inraoperative facial nerve identification. Clin Anat. 2007 Oct; 20(7): 739-44.

6. Rea PM, McGarry G, Shaw-Dunn J. The precision of four commonly used surgical landmarks for locating the facial nerve in anterograde parotidectomy in humans. Ann Anat. 2010 Feb 20; 192(1): 27-32.

7. Ali NS, Nawaz A, Rajput S, Ikram M. Parotidectomy: a review of 112 patients treated at a teaching hospital in Pakistan. Asian Pacific J Cancer Prev. 2010; 11:1113-5.

8. Rahman MA, Alam MM, Joarder AH. Study of nerve injury in parotid surgery. Nepalese J ENT Head Neck Surg. 2011; 2(1): 17-9.

9. Eng CY, Evans AS, Quraishi MS, Harkness PA. A comparison of the incidence of facial palsy following parotidectomy performed by ENT and non - ENT surgeons. J Laryngol Otol. $2007 \mathrm{Jan}$ 121(1): 40-3.

10. Dimitrov SA. Our experience with surgical dissection of the facial nerve in parotid gland tumours. (A preliminary report). Folia Med (Plovdiv). 2000; 42(1): 37-40.

11. Pather N, Osman M. Landmarks of the facial nerve: implications for parotidectomy. Surg Radiol Anat. 2006 May; 28(2): 170-5.

12. Conley J. Search for and identification of the facial nerve. Laryngoscope. 1978 Jan; 88(1 Pt 1): $172-5$.

13. Reid AP. Surgical approach to the parotid gland. Ear Nose Throat J. 1989 Feb; 68(2): 151-4.

14. Tabb H, Scalco A, Fraser SF. Exposure of the facial nerve in parotid surgery. Laryngoscope. 1970 Apr; 80(4): 559-77.

15. Witt RL. Facial nerve function after partial superficial parotidectomy: an 11 - year review (1987 - 1997). Otolaryngol Head and Neck Surg. 1999 Sep; 121(3): 210-3.

16. Pereira, JA, Meri A, Potau JM, Prats - Galino A, Sancho JJ, Sitges - Serra A. A simple method for safe identification of the facial nerve using palpable landmarks. Arch Surg. 2004 Jul; 139(7): 745-7. 